del contorno de la misma, tiene una alta sensibilidad y especificidad para el diagnóstico de la rotura testicular ${ }^{4}$. El diagnóstico inmediato y la pronta reparación condicionan la viabilidad del testículo, con la preservación del parénquima testicular y su función hormonal, así como condiciona también la disminución de las complicaciones tardías, tales como el dolor crónico, la atrofia testicular y en última instancia la orquiectomía.

En ausencia de signos de severidad, el tratamiento médico con vigilancia periódica puede estar justificada. Sin embargo, ante una clínica sospechosa o hallazgos ecográficos dudosos, la mayoría de los autores recomiendan la cirugía exploradora ${ }^{5}$.

En ausencia de hematoceles, hematoma intratesticular de gran tamaño o rotura de la túnica albugínea, el tratamiento médico consistente en el reposo, la administración de fármacos antiinflamatorios y la suspensión testicular está instaurado ${ }^{6}$.

B I B L I O G R A F Í A

1. Buckley JC, McAninch JW. Diagnosis and management of testicular ruptures. Urol Clin North Am. 2006;33:111-6.
2. Andipa E, Liberopoulos K, Asvestis C. Magnetic resonance imaging and ultrasound evaluation of penile and testicular masses. World J Urol. 2004;22:382-91.

3. Pavlica P, Barozzi L. Imaging of the acute scrotum. Eur Radiol. 2001;11:220-8.

4. Deurdulian C, Mittelstaedt CA, Chong WK, Fielding JR. US of acute scrotal trauma: optimal technique,imaging findings, and management. Radiographics. 2007;27:357-69.

5. Buckley JC, McAninch JW. Use of ultrasonography for the diagnosis of testicular injuries in blunt scrotal trauma. J Urol. 2006;175:175-8.

6. Chandra RV, Dowling RJ, Ulubasoglu M, Haxhimolla H, Costello AJ. Rational approach to diagnosis and management of blunt scrotal trauma. Urology. 2007;70:230-4.

E. Tolosa Eizaguirre ${ }^{a, *}$, J.E. Robles García ${ }^{a}$, J. Lorente Pérez ${ }^{b}$ y A. Rincón Mayans ${ }^{a}$

aDepartamento de Urología, Clínica Universidad de Navarra, Pamplona, Navarra, España

bepartamento de Urología, Clínica San Miguel, Pamplona, Navarra, España

*Autor para correspondencia.

Correo electrónico: etolosaei@unav.es (E. Tolosa Eizaguirre).

\title{
Hidronefrosis prenatal secundaria a válvulas ureterales
}

\section{Prenatal hydronephrosis due to congenital ureteral valves}

\section{Sr. Director:}

Las válvulas ureterales representan una causa rara de obstrucción del tracto urinario superior. Desde que fueron descritas por Wolfler en 1877, muy pocos casos se han descrito en la literatura médica ${ }^{1} \mathrm{y}$, en casos aislados, han sido diagnosticadas previo a la cirugía ${ }^{2}$. En nuestro caso, la sospecha se originó antes del nacimiento, cuando las válvulas ureterales fueron consideradas durante el diagnóstico diferencial de hidronefrosis antenatal.

Presentamos el caso de un paciente de 4 meses de edad que presentó en la ecografía prenatal de control hidronefrosis severa del riñón derecho y dilatación del tercio superior del uréter. El sedimento de orina y el cultivo de orina fueron normales. El diagnóstico de hidronefrosis fue confirmado tras la realización de una ecografía 15 días después del nacimiento. La hidronefrosis fue ratificada por urografía intravenosa (fig. 1) y renograma diurético (DTPA-Tc99m/furosemida), en los cuales se observó descenso de la función y retraso en el drenaje del riñón afectado. La realización de la cistouretrografía descartó la presencia de reflujo vesicoureteral.
La pielografía anterógrada percutánea (fig. 2) confirmó y localizó de modo preciso la estenosis en el uréter proximal, sugiriendo el diagnóstico de válvula ureteral.

Ante el cuadro de hidronefrosis severa, se decidió realizar intervención quirúrgica en la que se evidenció dilatación del tercio proximal del uréter derecho, por lo que se llevó a cabo una resección de $2 \mathrm{~cm}$ de longitud del uréter, que abarcó la zona de diferencia de calibre, y anastomosis ureteroureteral término-terminal. El examen histológico del segmento ureteral resecado reveló fibras transversas de mucosa ureteral que contenían haces de musculatura lisa.

Un mes tras la cirugía, en el examen de control a través de la nefrostomía percutánea, se observó nueva reestenosis del uréter a nivel de la anastomosis ureteroureteral. Dicha reestenosis fue tratada con dilatación neumática, con resultado satisfactorio. El renograma diurético (DTPA-Tc99m/furosemida) mostró 3 años más tarde resolución completa de la hidronefrosis sin obstrucción.

La estenosis ureteral congénita y las válvulas ureterales son las principales causas de obstrucción ureteral congénita ${ }^{3}$. La embriogénesis de las válvulas ureterales se mantiene incierta, y actualmente se han sugerido tres teorías para explicar su 


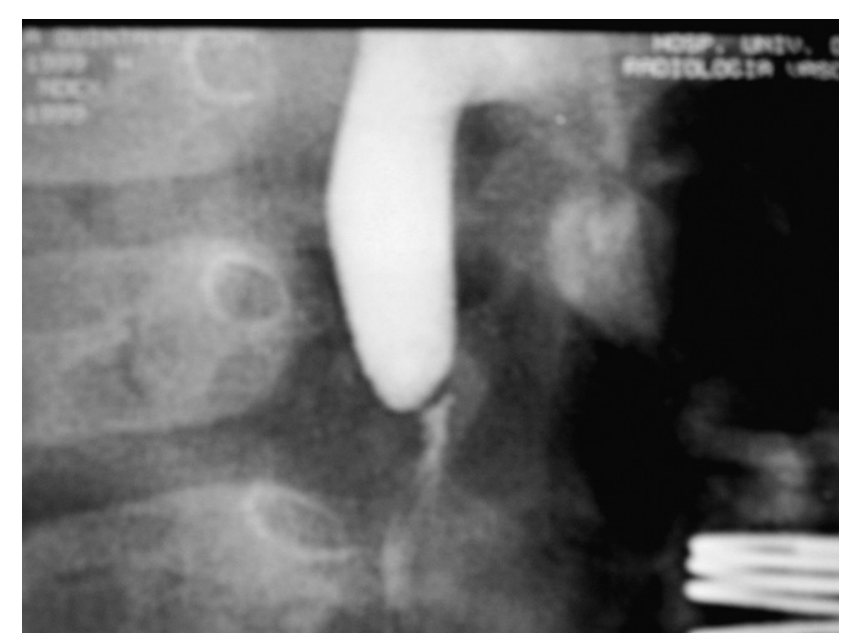

Figura 1 - Urografía intravenosa: hidroureteronefrosis de riñón derecho.

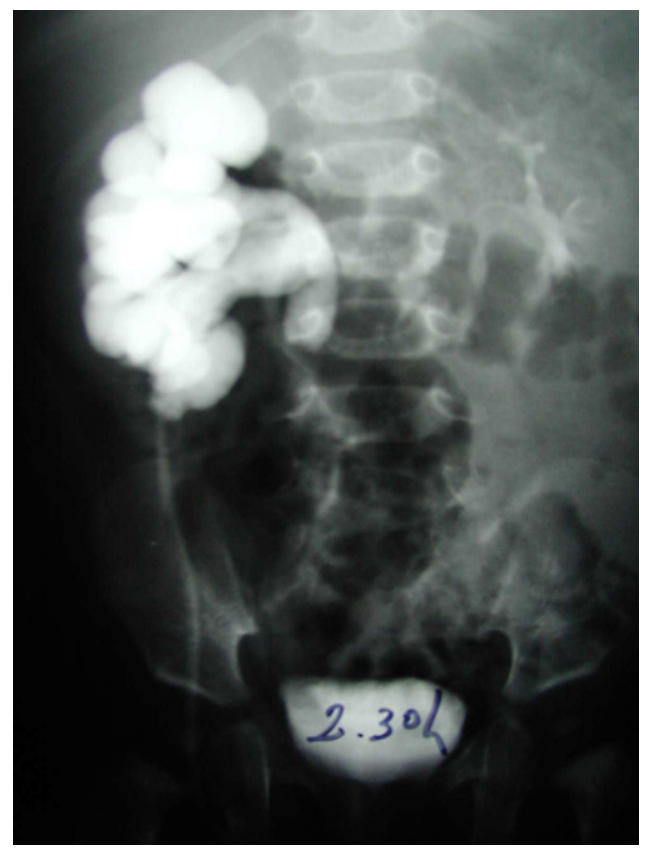

Figura 2 - Pielografía anterógrada percutánea: dilatación pielocalicial y uréter proximal derecho.

existencia: por un lado, la persistencia de la membrana de Chwalla; por otro lado se han descrito como pliegues fisiológicos en el lumen del uréter, y la tercera teoría se ha relacionado con una embriogénesis ureteral anormal. Las válvulas ureterales pueden presentarse en cualquier segmento del uréter, afectando por igual en frecuencia tanto al uréter derecho como al izquierdo, sin que se haya visto predilección por el sexo.

La presencia de anormalidades del tracto urinario se ha relacionado con un $45 \%$ de las válvulas ureterales del tercio superior y en un 39\% con las válvulas del tercio ureteral inferior y medio. De este modo, se ha relacionado con duplicaciones renales completas e incompletas, uréter ectópico, reflujo vesicoureteral y riñón en herradura. También se ha asociado a patologías como litiasis renales en un $17 \%$ e hipertensión arterial en un 14\% de los $\operatorname{casos}^{1,4}$.
El uso de la pielografía anterógrada preoperatoria para el diagnóstico de esta patología ha sido poco utilizada, puesto que la mayoría de los casos han sido diagnosticados mediante renograma diurético $\mathrm{y} / \mathrm{o}$ pielografía retrógrada ${ }^{5}$. Muchos casos son descubiertos durante la cirugía o la autopsia. En este caso clínico presentamos uno de los pocos casos diagnosticados preoperatoriamente por pielografía anterógrada y confirmado histológicamente. La información provista por esta técnica de imagen es a menudo crucial para el manejo de los pacientes, tanto que puede servir para confirmar la naturaleza de la lesión y localizar de modo preciso su nivel de localización.

El diagnóstico diferencial de las válvulas ureterales es difícil de establecer. Principalmente incluye pliegues fetales no obstructivos, obstrucción de la unión pelviuretérica, estenosis ureteral distal, reflujo vesicoureteral y megauréter primario ${ }^{3}$. Característicamente, las válvulas ureterales están conformadas por pliegues transversos de fibras musculares tapizados por mucosa urotelial, mientras que las estenosis congénitas tienen un estrechamiento del lumen sin cambios estructurales en la mucosa ${ }^{1}$; por otro lado, el megauréter primario normalmente muestra únicamente dilatación ureteral.

Indudablemente, el diagnóstico y el tratamiento precoces de la obstrucción ureteral son cruciales para preservar la función renal. El tratamiento quirúrgico consiste en la escisión quirúrgica del segmento que contiene la válvula y en la anastomosis término-terminal. No obstante, el desarrollo de técnicas mínimamente invasivas, como el tratamiento endoscópico, llevando a cabo escisiones o ablaciones con láser de la válvula ureteral, han sido utilizados con buenos resultados ${ }^{6,7}$. En nuestro caso, el uso de estas técnicas mínimamente invasivas, tal y como fue la dilatación neumática, permitió resolver exitosamente la reestenosis postoperatoria, evitando de este modo una nueva intervención quirúrgica así como una mayor morbilidad asociada a una nueva intervención ${ }^{8}$.

B I B L I O G R A F Í A

1. Rabinowitz R, Kingston TE, Wesselhoeft C, Caldamone AA. Ureteral valves in children. Urology. 1998;51:7-11.

2. Tartari F, Bezhani E, Rota T, Subashi S, Shehu M, Harito F, et al. Ureteral valves associated with ureteral stricture. Report of 4 cases. Eur Urol. 1998;33:412-3.

3. Cauchi JA, Chandran H. Congenital ureteric strictures: An uncommon cause of antenatally detected hydronephrosis. Pediatr Surg Int. 2005;21:566-8.

4. Rossi E, Salas J, Aucatoma F, Muñoz M, Fochs L. Congenital ureteral valves: Two new cases and a review of the literature. J Pediatr Urol. 2007;3:344-9.

5. Tlili-Graies K, Allègue M, Kraiem C, Ben Romdhane MH, Bakir D, Laarif $\mathrm{M}$, et al. Ureteral valves: Report of a case diagnosed by anterograde pyelography. Pediatr Radiol. 1988;19:67-9.

6. Nishio S, Hamada H, Yokoyama M. Endoscopic incision for the treatment of a ureteric valve. BJU Int. 1999;83:1081-2.

7. Singh SK, Wadhwa P. Ablation of diaphragmatic annular ureteral valve with holmium laser. Int Urol Nephrol. 2006;38: 157-159.

8. Martí Malet J, Lopez Llauradó H, Izquierdo de la Torre F. Ureteral stenosis and pneumatic dilatation. Arch Esp Urol. 2001;54:627-36. 
L. Delgado-Plasencia ${ }^{a, *}$, N. Hernández-Siverio ${ }^{b}$

y D. Castro-Díaz

${ }^{a}$ Servicio Cirugía General y Digestiva, Hospital Universitario de Canarias, Canarias, España

bServicio de Urología y Urología Pediátrica, Hospital Universitario

de Canarias, Canarias, España
*Autor para correspondencia.

Correos electrónicos: lucianodelgado1@gmail.com, luciano_delgado1@yahoo.es (L. Delgado-Plasencia).

\section{Metrorragias como forma de presentación de un carcinoma de células renales con metástasis ovárica}

\section{Methroragies as form of presentation of a ovary metastases from a primary renal cell carcinoma}

\section{Sr. Director:}

Presentamos el caso de una mujer de 52 años que consultó por episodios repetidos de metrorragias así como síndrome general consistente en astenia y anorexia. A la exploración no llamaba nada la atención tan solo restos hemorrágicos en la exploración vaginal. Una ecografía vaginal evidenció la presencia de una masa sólido quística dependiente del anejo izquierdo, confirmándose posteriormente por TC (fig. 1), con pequeña cantidad de líquido libre intraperitoneal. Así mismo, el TC evidenció la presencia de una masa sólida de $6,5 \times 6,5 \mathrm{~cm}$ dependiente del polo inferior del riñón derecho (fig. 2), así como múltiples nódulos en polo superior. Se practicó nefrectomía radical derecha así como histerectomía y ooforectomía bilateral siendo informada la pieza renal como carcinoma de células claras Furhman III, sin invasión de la

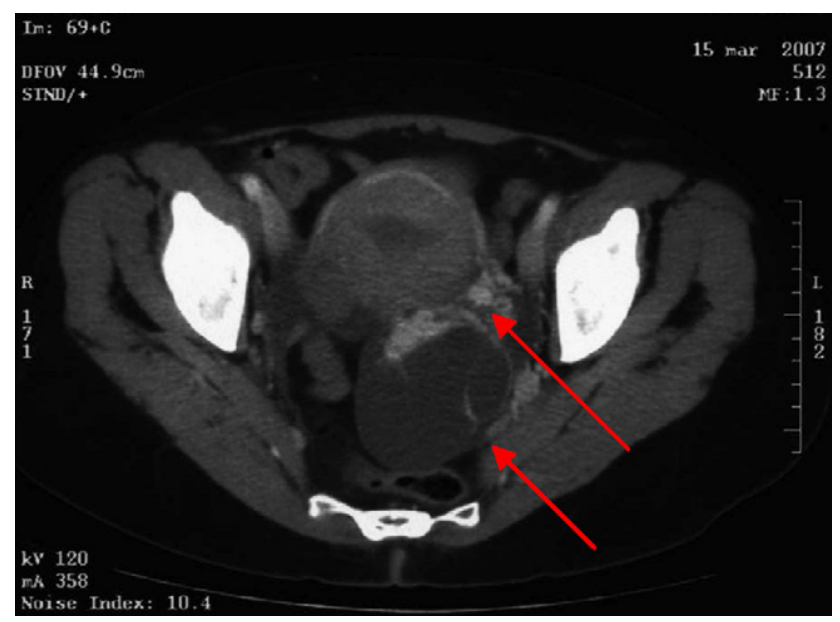

Figura 1 - TC. Componente sólido quístico de la masa anexial (flecha).

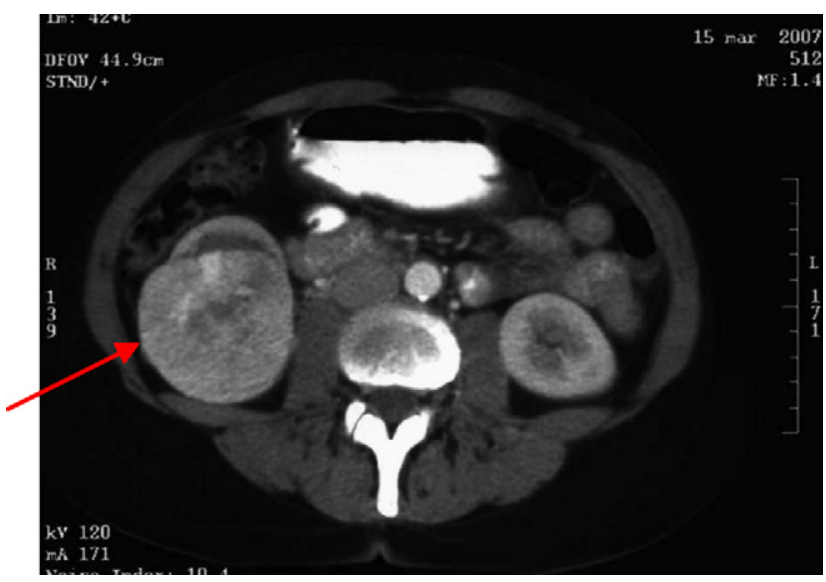

Figura 2 - TC. Masa compleja de $65 \times 65 \mathrm{~mm}$ dependiente del polo inferior del riñón derecho (flecha).

cápsula renal, mientras que el ovario derecho presentaba metástasis de carcinoma renal de células claras.

La metástasis ovárica de la adenocarcinoma renal de la célula es absolutamente rara. Se confunden a menudo con tumores claros primarios de la célula del ovario. Aproximadamente un tercio de los pacientes con nuevo diagnóstico de carcinoma renal presentarán enfermedad metastásica de inicio $^{1}$. Por otro lado, cerca de la mitad de los pacientes que son nefrectomizados con intención curativa, sufrirán metástasis a distancia durante el seguimiento ${ }^{2,3}$. El 70\% de las metástasis están limitadas a un solo órgano, generalmente pulmón (40\%) o hueso (22\%), siendo únicas en el 2,3\% de los casos $^{4}$. Con tan solo 12 casos publicados en los últimos 20 años, la afectación metastásica del ovario con primario de origen renal es extremadamente rara, pero la afectación metastática de un carcinoma renal debe ser incluida en el diagnóstico diferencial de los tumores de ovario con histología de célula clara 5 . 